\title{
Efficiency of Online Course of Medical Statistics in Nanjing Medical University During the COVID-19 Epidemic
}

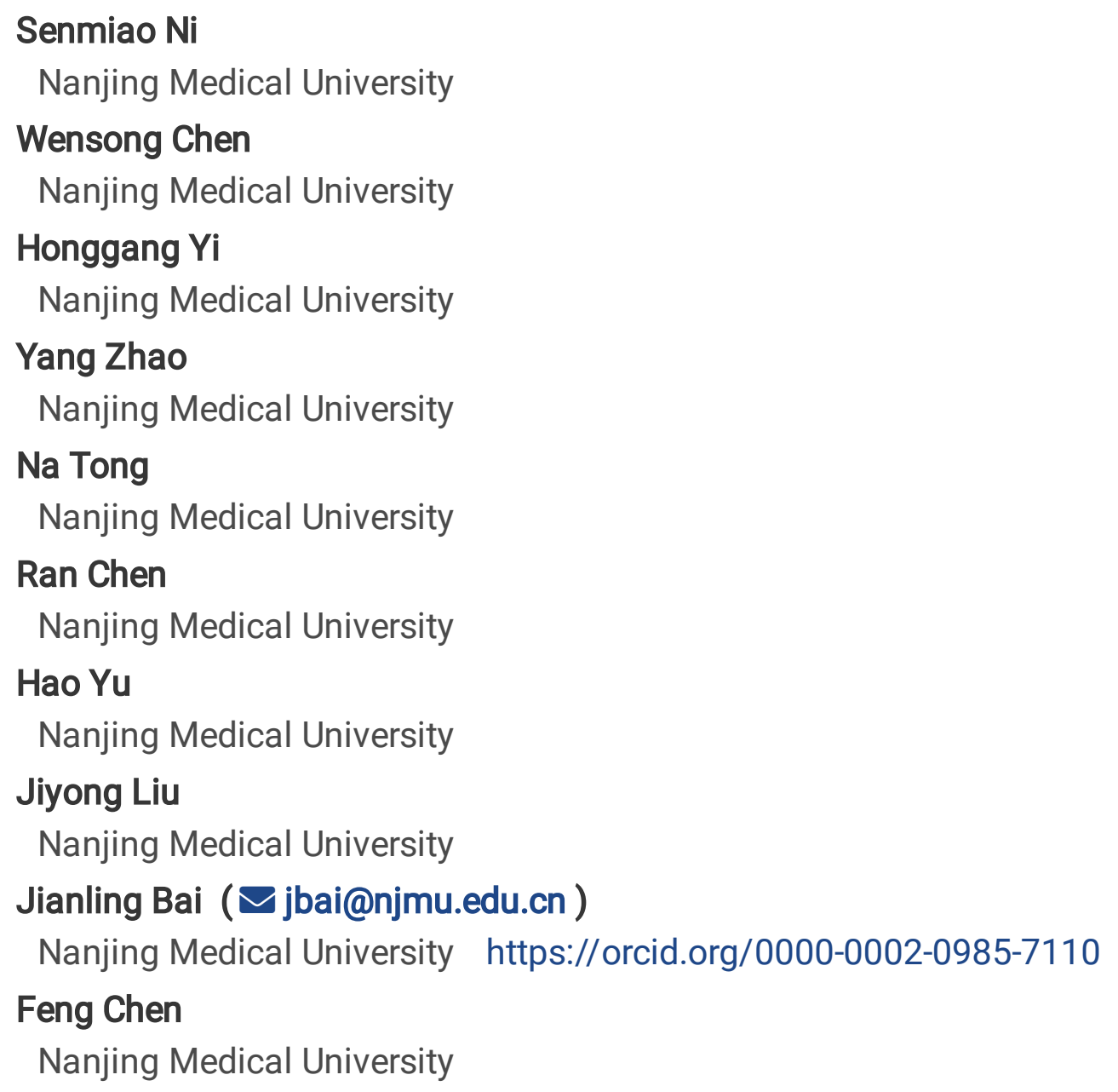

\section{Research article}

Keywords: COVID-19, Medical Statistics, Online Teaching, MOOC

Posted Date: August 4th, 2020

DOI: https://doi.org/10.21203/rs.3.rs-42890/v1

License: (c) (1) This work is licensed under a Creative Commons Attribution 4.0 International License. Read Full License 


\section{Abstract}

Background: To analyze the online course efficiency of a combined mode of Massive Open Online Course (MOOC) micro-video and E-learning platform in Nanjing Medical University during the COVID-19 epidemic.

Methods: We developed a new questionnaire to assess the efficiency of online teaching of medical statistics in Nanjing Medical University. This investigation enrolled students participating in the online course of medical statistics from January 2020 to June 2020. The "Questionnaire Star" electronic questionnaire collection system was used to collect data.

Results: In total, 1050 of the 1210 (86.78\%) students completed the questionnaire, including 971 (92.48\%) juniors. To be specific, $57.33 \%$ of the students majored in clinical medicine, $15.14 \%$ in pharmacy, $10.38 \%$ in pediatrics, $8.00 \%$ in medical imageology, and $6.29 \%$ in basic medicine. As to the question "Are you satisfied with the current online teaching method?", 354 (32.77\%) students responded with "Agree" and "Strongly Agree", and 1012 (96.47\%) thought they needed to consolidate what they had learned after returning to school. Most students reported their "Difficulties in the learning process" by "Learning motivation" and "Personal inertia" (59.90\% and 58.29\%, respectively).

Conclusions: The online course of medical statistics was favored by most students, suggesting its efficiency an efficient alternative to classroom study during the COVID-19 pandemic. Yet there were still some problems, such as inconvenient communication between teachers and students, poor mastery of key knowledge, which should be resolved in classroom teaching at school.

\section{Background}

The World Health Organization (WHO) has declared a global COVID-19 pandemic.[1-3]The COVID-19 pandemic has led to the closure of schools in many countries.[4, 5] In the Department of Biostatistics of Nanjing Medical University (NMU), Medical Statistics (MS) was taught through an online mode combining MOOCs (massive open online courses) as course resources, E-learning of Nanjing Medical University as a secondary teaching platform, and QQ group as an online Q\&A platform.

In NMU, MS is a compulsory course designed for majors in clinical medicine, stomatology and preventive medicine. Since its launch in 2018, the course has seen more than 20,000 learners. In the previous semesters, the course was taught in the flipped class based on MOOCs and online/offline teaching tools. [6-8]

During COVID-19 epidemic, the course has been open to 1,210 students at NMU through online MOOCs platform. The online teaching methods are shown in Figure 1. To evaluate the online teaching efficiency of MS, we carried out an empirical investigation.

\section{Methods}




\subsection{Questionnaire design}

Based on our previous studies about online teaching, we developed a questionnaire to evaluate the teaching efficiency of online MS for this study. The design of the questionnaire was reviewed by the team at MS.

The questionnaire consisted of four parts. The first part was about the characteristics of participants, the second part about the attitude towards statistics, the third part about learning status, the fourth part about student evaluation, including self-assessment and curriculum evaluation. Most options of questionnaire are on the scale of 1 (Bad) to 5 (Excellent). The main part is listed in Table 1 and more details of the questionnaire are presented in the additional document (see Additional file 1).

\subsection{Data Collection and Analysis}

The survey was conducted online through "Questionnaire Star" electronic questionnaire collection system. Researchers sent the electronic questionnaire link and informed students that they were voluntary to complete the survey. The participants were sophomores or juniors who studied medical statistics in the 2020 spring semester in NMU. A total of 1210 students were enrolled from six majors, such as clinical medicine, basic medicine and pharmacy. A total of 1050 participants returned questionnaires, with a response rate of $86.78 \%$.

Both frequencies and percentages for categorical variables (such as gender, region, grade, length of schooling, major and grade of various indicators, and so on) were calculated. SAS 9.4 and Excel 2019 were used for statistical analysis.

\section{Results}

\subsection{Basic characteristics of students}

As shown in Table 2, juniors (about 92.48\%) accounted for the majority. All the students were from fouryear, five-year, eight-year academic programs. Students in clinical medicine made up the largest proportion (57.33\%), followed by those in pharmacy (15.14\%) and pediatrics $(10.38 \%)$. The proportion of female students (56.86\%) was slightly higher than that of male students $(43.14 \%)$.

Most students chose "Average" $(55.52 \%, 63.14 \%)$ or "Good" $(31.24 \%, 26.48 \%)$ when they were asked to self-assess their mathematical knowledge and logical thinking. When they were asked to self-assess their computer knowledge, 595 (56.67\%) chose "Average", 235 (22.38\%) chose "Fair", and only 141 (13.43\%) chose "Good" or "Excellent".

\subsection{Attitude towards statistics}

As shown in Figure 2, except those answering by "I am interested in the course of medical statistics", the distributions of the answers to the other four questions were nearly the same, with "Agree" and "Strongly 
Agree" accounting for more than $70 \%$. As to questions "Medical statistics is useful to my major scientific research" and "Mastering the use of a statistical software is very helpful to my work/scientific research", "Agree" and "Strongly Agree" accounted for more than $80 \%$, indicating that these students knew the importance of MS in scientific research. Another 600 students $(57.14 \%)$ held a neutral view of "I am interested in the course of medical statistics." Therefore, efforts should be made to enhance their interests in MS.

\subsection{Learning status}

(1) Pre-class preview

The students' pre-class learning efficiency was not ideal. As shown in Figure 3, most students reported to have occasional pre-class preview (70.38\%), and the preview time was less than 30 minutes $(79.81 \%)$. Reading textbooks and watching online videos were two commonest preview ways, chosen by $71.14 \%$ and $27.62 \%$ of the total students, respectively. A small number of students chose "classmate discussion" (13 students, 1.24\%); 881 students (83.9\%) responded that the preview was "somewhat helpful" for class learning, while 54 students (5.14\%) responded that it was "not helpful". Therefore, it needs teachers to guide pre-class preparation before online teaching.

(2) Attending class

Most students could accomplish the course online (69.24\%), and most students had taken notes (90.74\%). To be specific, $41.14 \%$ of the students had "occasionally watched the video (such as: watching the video only to complete the learning task, playing the course video but not watching it)". It implied that, during online learning, the students may not be fully devoted themselves to the courses; thus the teachers should maintain students' attention through efforts like proposing questions, asking students to answer questions immediately, and assigning homework. Online learning terminals and websites are shown in Figure 4. Most students believed that the existing network, usually WIFI (82.86\%), can guarantee the online learning. Laptop and mobile phone were the most used terminals $(71.14 \%, 61.14 \%$, respectively).

(3) After-class review

In after-class learning, $90.0 \%$ of the students said that they would review after class, and $92.67 \%$ could finish the homework within half an hour after class. However, teacher-student interaction was insufficient, as reflected by only $15 \%$ of students communicating with teachers regularly. Regarding the use of statistical software, 885 students $(84.29 \%)$ said that they had never used any statistical software, while $55(5.24 \%)$ and $38(3.62 \%)$ students had used STATA and R, respectively.

\subsection{Student evaluation}

(1) Self-assessment 
The result of "diligence in this semester" deserves our attention: $68.95 \%$ of students thought their diligence in this semester was "Average", while $11.14 \%$ thought they had no intention at all. In terms of "grade requirements for the course", $35.24 \%$ and $57.71 \%$ of the students evaluated themselves as "Excellent and Pretty good" and "Good", respectively, while 6.95\% as "Not bad". This is a big difference between students' expected performance sand the performances achieved by their diligence, indicating that the students' motivation should be enhanced in the online MS class.

As for the "knowledge of medical statistics", $70.67 \%$ responded with moderate and $17.24 \%$ as poor. The proportion of students with a good mastery has a negative association to the difficulty of the chapters. For example, these proportions were $81.71 \%, 79.43 \%$ and $71.14 \%$ in regard to three easy chapters "statistical description", "normal distribution" and "sampling error"; and 64.67\%, 61.14\%, 57.43\% in regard to three difficulty chapters "chi-square test", "t test" and "rank sum test", respectively. In the evaluation of "level of communication with teachers and classmates ", 64.95\% of the students chose "Good" or "Not bad".

(2) Curriculum evaluation

As shown in Figure 5, most students chose "Good" or "Pretty good" in terms of "video quality" and "the quality of the homework ". This result is basically consistent with that of "satisfied with the current online teaching method" since "relatively satisfied "and" very satisfied" were only reported in $32.77 \%$ of the students. To the questions such as "level of teachers", "teacher's teaching attitude", "teaching content structure", "practicality taught in the course", $60 \%$ responded with "Pretty good" or "Excellent". For example, 76.38\% students responded with "Pretty good" or "Excellent" to the "level of teachers" and $80.57 \%$ to the "teacher's teaching attitude". The proportion of students with satisfaction equal to the proportion of those choosing "satisfactory" and "very satisfied".

Nearly $60 \%$ of the students rated overall evaluation of the course as "Pretty good" and "Excellent", and $37.81 \%$ thought it was "Good". It is worth noting that 893 students (85.05\%) preferred "classroom teaching", indicating that the students are not used to pure online learning. The vast majority of students agreed that they needed to consolidate what they had learned after returning to school. Among them, $30.57 \%$ thought that it was necessary to "make up the missed lessons and explain them one by one", while $65.81 \%$ thought that it was necessary to "focus on some chapters or answer questions". Therefore, these questions should be resolved by after-epidemic classroom teaching.

For "the biggest problem and challenge encountered in online learning", most students chose "learning motivation problem"(59.9\%), "personal inertia problem"(58.29\%) and "solving difficult problems"(43.05\%). A considerable number of students had problems in "learning resources", "platform issues" and "network issues" too. In addition, 267 (25.43\%) students felt barriers between the teacher-student interactions, indicating that a good interaction was not established in online teaching.

\section{Discussion}


In this study, we conducted a survey aiming to evaluate the efficiency of online course of MS. In general, the online course of MS conducted by Department of Biostatistics of NMU can achieve the basic teaching purpose. Specifically, almost all students $(97.81 \%)$ thought the overall quality of the online course was good enough. Additionally, a similar proportion of students thought the teacher's teaching attitude, the quality of video and homework were "Good", "Pretty good" or "Excellent".

Although learning online courses at home was an alternative way to study at school for students during the COVID-19 pandemic, there are shortcomings like inconvenience for teacher to monitor students' study activities and difficulty for students to interact with teachers during online class and out of class. For example, based on the answers to "the biggest problem and challenge encountered in online learning", the top three problems are "learning motivation problem"(59.9\%), "personal inertia problem"(58.29\%) and "solving difficult problems"(43.05\%). In addition, 25.43\% students felt barriers between the teacherstudent interactions. Based on these investigational results, we proposed some suggestions for MS teachers in medical school to develop a better strategy for the online course.

\subsection{Enhancing students' independent course preparation}

To study MS, students should focus on the understanding and application of statistical methods. If the students do not preview before class and rely only on the teacher's in-class explanation, it is difficult for them to master the knowledge of MS. Teachers should guide students to study independently and effectively. At the same time, teachers should supervise students' preparation before class, so that the preparation can really help the students to attain the learning materials in the follow-up teaching.

\subsection{Increasing teacher-student interactions}

Internet provides a platform for the communication between teachers and students in universities, but this platform has not been properly used [9]. Lee found that students did not want to watch slides without the lecturer's face or voice, and suggested instructors should increase teacher-student interactions, including inviting student to engage into various online learning activities and encouraging student to provide course feedback [10]. Through ways like after-class discussion and questionnaire, the teachers could fix the loopholes in online teaching. An efficient online teaching mode can only be established through the smooth cooperation between teachers and students.

\subsection{Evaluating the learning of students on a regular basis}

Instructors should take the initiative to evaluate students' learning through short quizzes and homework to make sure students understand what have been discussed in online class. At the end of the class, students should be asked to share their learning experience and notes through the "Forum Discussion" module in the online class system. Finally, the teacher should make an overall evaluation on the performance of all the students in his/her class. Based on the students' learning status, teachers should carry out targeted tutoring [11]. 


\section{Conclusions}

During the COVID-19 pandemic, the transition from traditional class to online class of teaching medical statistics could achieve the teaching purpose, which was favored by most students. But there were still some problems, such as inconvenient communication between teachers and students, poor mastery of key chapters, and so on, which required further improvement in the future.

\section{Abbreviations}

NMU: Nanjing Medical University; MS: Medical Statistics; MOOC: Massive Open Online Course; COVID-19: Corona Virus Disease 2019

\section{Declarations}

\section{Ethics approval and consent to participate}

The Ethics Committee of Institutional Review Board in Nanjing Medical University determined that this study ethical did not required approval. This study did not include experiments on animal or human subjects. Consent was received by electronic questionnaire from the participants to use the information anonymously for this study.

\section{Consent for publication}

Not applicable.

\section{Availability of data and material}

Not applicable.

\section{Competing interests}

The authors declare that they have no competing interests

\section{Funding}

The work was supported by grant from the Key Project of Nanjing Medical University Graduate Education Reform Project (SPOC Special) (SPOCZD201906 to JLB), and the Nanjing Medical University 2019 Educational Research Project (2019ZC008 to JLB, 2019LX035 to JYL). The funding body did not have any role in the design of the study and collection, analysis, and interpretation of data and in writing the manuscript.

\section{Authors' contributions}


SMN, WSC and JLB designed the questionnaire and the research; SMN and WSC collected the data, did the statistical analysis and wrote the manuscript; HGY, YZ, NT, RC, HY and JLB provided the critical revision of the manuscript for important intellectual; FC囚JLB and JYL supervised this work; JLB and JYL provided financial support. All authors read and approved the final manuscript.

\section{Acknowledgements}

Not applicable.

\section{References}

1. Cucinotta D, Vanelli M: WHO Declares COVID-19 a Pandemic. Acta bio-medica : Atenei Parmensis 2020, 91(1):157-160.

2. Sun P, Lu X, Xu C, Sun W, Pan B: Understanding of COVID-19 based on current evidence. Journal of medical virology 2020.

3. Sohrabi C, Alsafi Z, O'Neill N, Khan M, Kerwan A, Al-Jabir A, losifidis C, Agha R: World Health Organization declares global emergency: A review of the 2019 novel coronavirus (COVID-19). International journal of surgery (London, England) 2020, 76:71-76.

4. Peng F, Tu L, Yan Y, Hu P, Wang R, Hu Q, Cao F, Jiang T, Sun J, Xu G et al: Management and Treatment of COVID-19: The Chinese Experience. The Canadian journal of cardiology 2020.

5. Li X, Wang W, Zhao X, Zai J, Zhao Q, Li Y, Chaillon A: Transmission dynamics and evolutionary history of 2019-nCoV. Journal of medical virology 2020, 92(5):501-511.

6. Bai J, Chen F, Zhao Y, Yi H, Yu H, Wei Y, Lou D, Peng Z: Biostatistics flipped classroom teaching based on MOOC. Chinese Journal of Health Statistics 2017, 34(05):829-831.

7. Milic NM, Trajkovic GZ, Bukumiric ZM, Cirkovic A, Nikolic IM, Milin JS, Milic NV, Savic MD, Corac AM, Marinkovic JM et al: Improving Education in Medical Statistics: Implementing a Blended Learning Model in the Existing Curriculum. PloS one 2016, 11(2):e0148882.

8. Peng Z, Zhao Y, Yi H, Bai J, Lou D, Yu H, Chen F: The Application of PBL Teaching Mode in Medical Statistics. CHINA HIGHER MEDICAL EDUCATION 2010(03):79-81.

9. Xia X, Yuan Z: On Teacher-Student Relation Construction in Virtual Interactive Context. Heilongjiang Researches on Higher Education 2020, 38(03):148-151.

10. Gewin V: Five tips for moving teaching online as COVID-19 takes hold. Nature 2020, 580(7802):295296.

11. He Y, Gan L, Chen X, Kong X, Jia Z: Problems and Solutions on the Status Quo of the Communication between the Teachers and Students of Southwest Jiaotong University. Journal of Southwest Jiaotong Universit (Social Science) 2014, 15(05):111-115.

\section{Tables}


Table 1 The Core QuestionS of The Investigation

D1. In this semester, do you think your study diligence is?

D2. In this semester, do you think your knowledge of this course is?

D3. In this semester, your level of communication with teachers and classmates is?

D4. In this semester, what are your grade requirements for the course?

E1. What do you think of the video quality of the course?

E2. What do you think of the teaching structure of the course?

E3. What do you think of the online teaching method of the course?

E4. What do you think of the practicality taught in the course?

E5. What do you think of the quality of the homework after class?

E6. What do you think of the teacher's teaching level?

E7. What do you think of the teacher's teaching attitude?

Table 2 Basic information of students 


\begin{tabular}{|c|c|c|c|}
\hline \multicolumn{2}{|l|}{ Variables } & \multirow{2}{*}{$\begin{array}{l}\text { Frequency (Total:1050) } \\
453\end{array}$} & \multirow{2}{*}{$\begin{array}{l}\text { Percentage (\%) } \\
43.14\end{array}$} \\
\hline Gender & Male & & \\
\hline & Female & 597 & 56.86 \\
\hline \multirow[t]{5}{*}{ Region } & Municipality & 156 & 14.86 \\
\hline & Prefecture level city & 279 & 26.57 \\
\hline & County level city & 374 & 35.62 \\
\hline & Town & 117 & 11.14 \\
\hline & Village & 124 & 11.81 \\
\hline \multirow[t]{2}{*}{ Grade } & Sophomore & 79 & 7.52 \\
\hline & Junior & 971 & 92.48 \\
\hline \multirow[t]{3}{*}{ Educational system } & Four-year & 118 & 11.24 \\
\hline & Five-year & 703 & 66.95 \\
\hline & Eight-year(5+3) & 229 & 21.81 \\
\hline \multirow[t]{6}{*}{ Major } & Clinical medicine & 602 & 57.33 \\
\hline & Basic medicine & 66 & 6.29 \\
\hline & Pharmacy & 159 & 15.14 \\
\hline & Pediatrics & 109 & 10.38 \\
\hline & Medical imageology & 84 & 8.00 \\
\hline & Medical laboratory science & 30 & 2.86 \\
\hline \multirow[t]{5}{*}{ Basic of mathematics } & Poor & 26 & 2.48 \\
\hline & Fair & 72 & 6.86 \\
\hline & Average & 583 & 55.52 \\
\hline & Good & 328 & 31.24 \\
\hline & Excellent & 41 & 3.90 \\
\hline \multirow[t]{5}{*}{ Basic of computer } & Poor & 79 & 7.52 \\
\hline & Fair & 235 & 22.38 \\
\hline & Average & 595 & 56.67 \\
\hline & Good & 126 & 12.00 \\
\hline & Excellent & 15 & 1.43 \\
\hline
\end{tabular}




\begin{tabular}{llcc|} 
Logic Thinking & 16 & 1.52 \\
\hline Foor & 48 & 4.57 \\
\hline Average & 663 & 63.14 \\
\hline Good & 278 & 26.48 \\
\hline Excellent & 45 & 4.29 \\
\hline
\end{tabular}

\section{Figures}

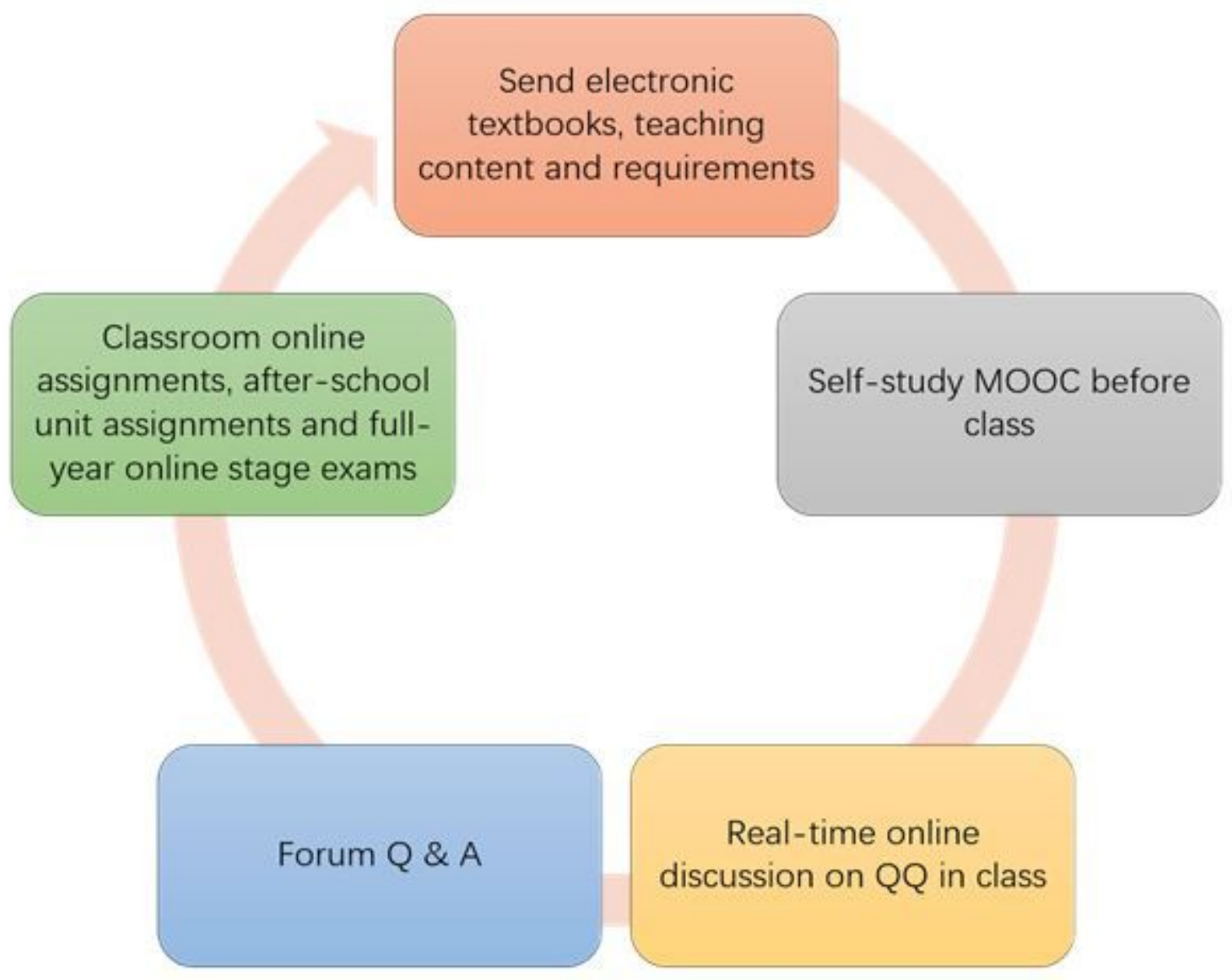

\section{Figure 1}

Online teaching method of medical statistics. 
1. I'm interested in the course of medical statistics.

2. Medical statistics is useful for my professional scientific research.

3. Mastering the use of a statistical software is very helpful to my work/scientific research.

4. The results of statistics can be applied to everyday work.

5. In the future work/scientific research, I will further learn the knowledge of statistics.
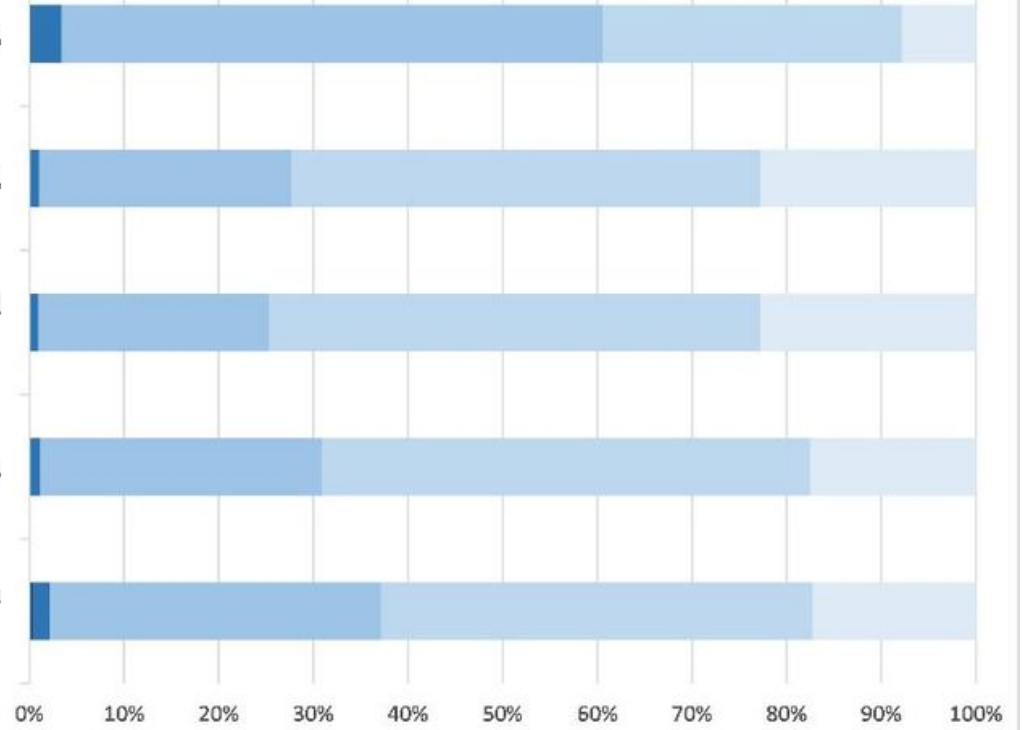

घ Strongly Against $=$ Against $=$ Neutral $=$ Agree $\quad$ Strongly Agree

\section{Figure 2}

Attitude towards statistics

A Always (5 times above): $10.38 \%$

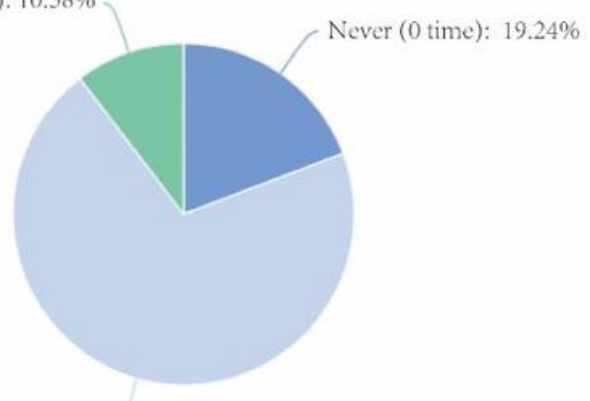

Sometimes ( $1-5$ times): $70.38 \%$

C

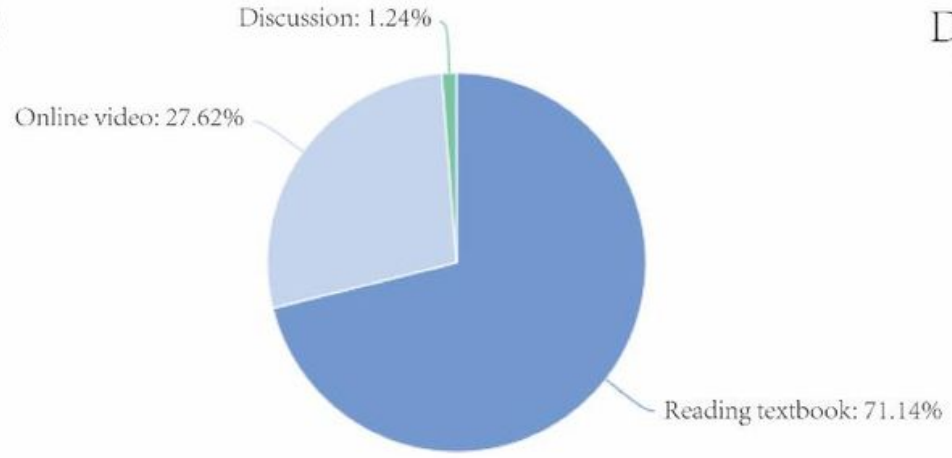

B

60 mins above: $4 \%$

30-60 mins: $16.19 \%$

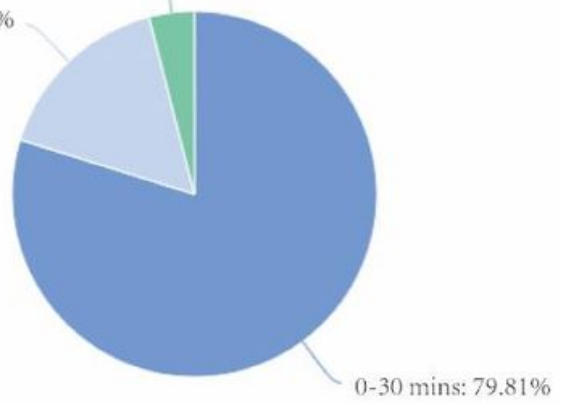

D) No helpful: $5.14 \%$

Very helpful: $10.95 \%$

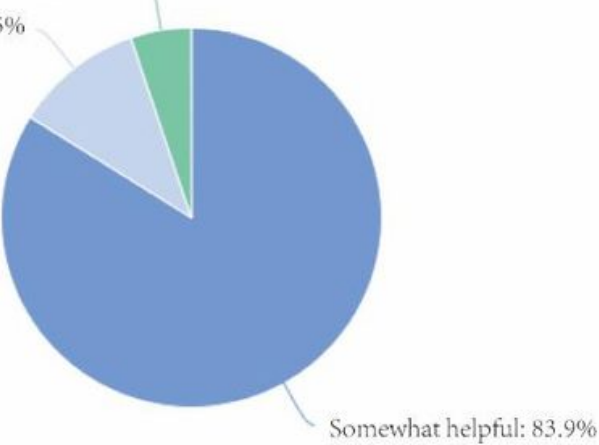

\section{Figure 3}

Pre-class learning: (A) preparation;(B) preparation time;(C) preparation methods;(D) preview effect. 


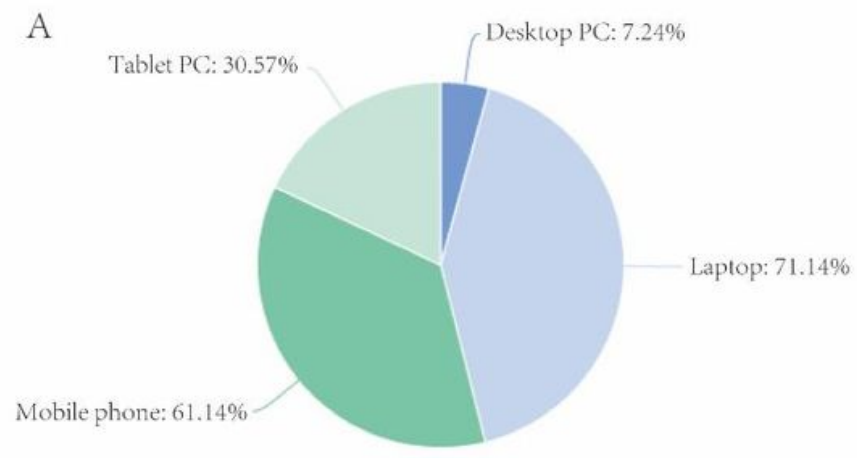

B

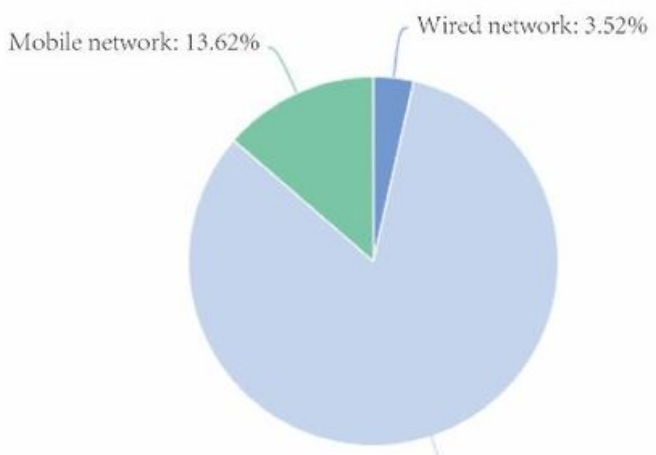

WIFI: $82.86 \%$

\section{Figure 4}

Online learning terminal and network usage: (A) learning terminal selection;(B) network use.

D1. In this semester, do you think your study diligence is?

D2. In this semester, do you think your knowledge of this course is?

D3. In this semester, your level of communication with teachers is?

D4. In this semester, what are your grade requirements for the course?

E1. What do you think of the video quality of the course?

E2. What do you think of the teaching structure of the course?

E3. What do you think of the online teaching method of the course?

E4. What do you think of the practicality taught in the course?

E5. What do you think of the quality of the homework after class?

E6. What do you think of the teacher's teaching level?

E7. What do you think of the teacher's teaching attitude?

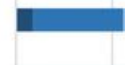

\section{-}

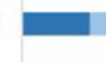

\footnotetext{
.
} 